\title{
A computational approach for modeling the role of the focus visual attention in an object categorization task Roberto A Vazquez* and Humberto Sossa
}

\author{
Address: Center for Computing Research, National Polytechnic Institute, Mexico City, 07738, Mexico \\ Email: Roberto A Vazquez* - ravem@ipn.mx \\ * Corresponding author
}

from Eighteenth Annual Computational Neuroscience Meeting: CNS*2009

Berlin, Germany. 18-23 July 2009

Published: 13 July 2009

BMC Neuroscience 2009, 10(Suppl I):P3I0 doi:I0.I I86/I47I-2202-I0-SI-P3I0

This abstract is available from: http://www.biomedcentral.com/I47I-2202/I0/SI/P3 I0

(c) 2009 Vazquez and Sossa; licensee BioMed Central Ltd.

\section{Background}

Attention, which is an important tool to adapt the visual system to different perceptual tasks, can be allocated to different aspects of the environment and in different ways, ranging from the focused analysis of local features to the global registration of scene properties [1]. Directing attention on a visual stimulus (VS) leads to lower perceptual thresholds, faster reaction times and increased discrimination accuracy [2]. However if focus of attention (FA) includes a distracter, the discrimination accuracy tends to decrease [1].

\section{Proposal}

In this research, we investigate how by changing the size of FA the accuracy of an object categorization task increases. A network of bipolar neurons (NBN) was used to simulate the retinal ganglion cells that send the VS to the visual cortex. A dynamic associative model (DAM) [3], which changes their synapse connection strengths according to a VS based on the Hebbian learning rule was used to simulate the hierarchically cortical regions consisting at least of V1, V2, V4, posterior inferior temporal cortex, inferior temporal cortex, and anterior temporal cortical areas [4]. The FA is controlled by means of the NBN where each neuron is randomly activated using a Gaussian distribution with center on the object that appears in the VS and a radio (size of the focus) controlled by the standard deviation SD.

\section{Results and conclusion}

To test the accuracy of the model, a benchmark of images composed by $3 \mathrm{D}$ objects viewed from $0^{\circ}$ to $355^{\circ}$ was used. Each pixel of the VS converges to each neuron of the NBN where only the activated neurons project the information onto the input (LGN) of the DAM (see Figure 1). During the learning process, the model performed with $100 \%$ of accuracy using only four views of each object. Starting from a FA that covers the complete VS (including distracters), we observed that during the categorization process (for the rest of the views of the objects), the accuracy of the model increased when the size of FA was decreased. However, we also observed that if the size is smaller than a threshold, the accuracy starts to decrease (see Figure 2).

The model learned to distinguish objects accurately and the successful results suggest the proposal could serve as a

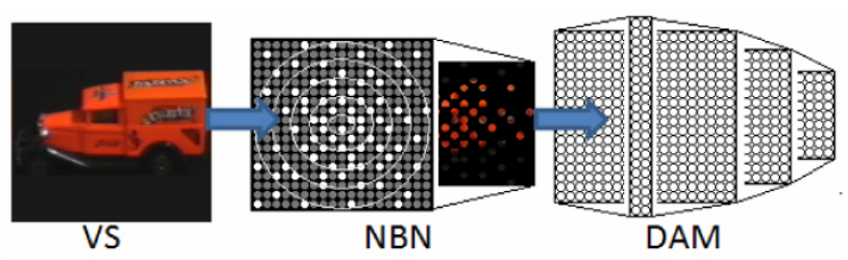

Figure I

Schematic representation of the model. 


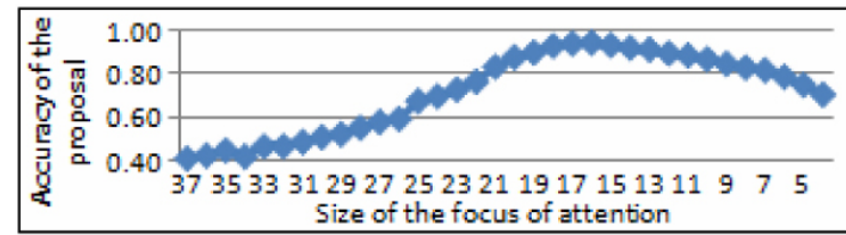

Figure 2

Behavior of the model.

biologically model to explain how the size of FA affects the accuracy in an object categorization task. Nowadays we are revising the way of controlling the size of the FA based on a feedback linked dopaminergic projections to the basal ganglia.

\section{Acknowledgements}

This work was supported by SIP-IPN under 20082948 and CONACYT under grant 46805 .

\section{References}

I. Treisman A: How the deployment of attention determines what we see. Vis Cogn 2006, I 4:4 I I-443.

2. Busse L, Roberts KC, Crist RE, Welssman DH, Woldorff MG: The spread of attention across modalities and space in a multisensory object. PNAS 2002, 102:1875I-I8756.

3. Vazquez RA, Sossa H: A new associative memory with dynamical synapses. Neural Process Lett 2008, 28:189-207.

4. Rolls ET, Stringer SM: Invariant visual object recognition: A model, with lighting invariance. Journal of Physiology-Paris 2006, 100:43-62.
Publish with Biomed Central and every scientist can read your work free of charge

"BioMed Central will be the most significant development for disseminating the results of biomedical research in our lifetime. "

Sir Paul Nurse, Cancer Research UK

Your research papers will be:

- available free of charge to the entire biomedical community

- peer reviewed and published immediately upon acceptance

- cited in PubMed and archived on PubMed Central

- yours - you keep the copyright 